\title{
Are Spatial and Systems Thinking Skills Identified in Turkish Primary Science Curriculum Enough for Geography Education?
}

\author{
Selçuk ŞAHINGÖZ1 \\ Kastamonu University, Kastamonu, TURKEY
}

${ }^{1}$ Assist. Prof. Dr.; Kastamonu University, Faculty of Education, Department of Educational Sciences, Kastamonu, TURKEY. ssahingoz [at] kastamonu.edu.tr. ORCID: 0000-0003-4884-7588

\begin{abstract}
Today, individuals need a solid understanding of how earth as a system works in order to understand and develop solutions for science-based issues affecting societies on a global scale such as natural disasters, global warming or COVID-19 pandemic. Humans also deliberate space investigations, such as interplanetary travels and life in space. Therefore, it is necessary to develop new skills to meet the requirements of the current world order overcome this kind of issues through science and geography education. Spatial and systems thinking skills are two of 21st century skills in teaching and learning science-related topics. The study purposes to examine current Turkish primary science curriculum regarding these skills. Document analysis method of qualitative research design was implemented in the study, Emergent qualitative analysis methods of content analysis and open coding were used. It is sought to analyze the research literature on geography education in order to delineate competences necessary for understanding societal problems related to earth science and astronomy-based physics units considering Turkish primary science curriculum framework. The findings of the study showed that the competences spatial and systems thinking skills should be more integral part of science curricula. Especially for spatial thinking skills, educators and policy makers should reconsider the learning objectives in primary science curriculum framework. In conclusion, the results indicated that spatial and systems thinking skills were partially acquired in the curricula. Some units should be clarified and enhanced depend on spatial thinking abilities, systems thinking abilities or both of them.
\end{abstract}

\section{Keywords}

Geography Education, Spatial Thinking Skills, Systems Thinking Skills, Turkish Primary Science Curriculum Framework 
The 21st century brings new requirements, but people have insufficient readiness to meet these needs. Many issues have been reconsidering such as economic, environmental, social, and cultural. Like other issues, education also goes through this adaptation process. Policymakers, educators, and teachers should integrate 21st century skills into education system. Aspect of geography education, we should raise geographically literate children for today's world (Schell \& Mohan, 2013). Because of this responsibility, geography should aim to gain students broaden worldview beyond as a course in secondary education (International Geographical Union, 2016). The Road Map for 21st Century Geographic Education (Bednarz, Heffron, \& Huynh, 2013) emphasizes essential role of geography education when facing societal issues in globalizing world. These issues are about public environmental protection, health, travel, economical concerns, social welfare, and international affairs. We can give today's hot topics space travel, global warming and the COVID-19 pandemic as examples.

Certain skills in geography education should be reviewed and embedded new skills to the curriculum. For this purpose, geographical thinking skills should be embedded in the learning objectives. To successfully implement geography education, teachers and educators must understand both geographical skills and how to integrate them to content and methods of geography. Bednarz, Heffron, and Huynh (2013) intend to relate elements of geography knowledge, skills, and problem-solving processes to develop through the components such as spatial thinking, visualization, systems thinking, and logical thinking. The study takes its inspiration for examining two of these components which are entitled spatial thinking skills and systems thinking skills.

Geography for Life: National Geography Standards (Geography Education Standards Project, 1994) describes geography as integrating knowing and doing. Geography for Life guideline has been considered with The World in Spatial Terms and The Uses of Geography to define the application of knowledge and understanding as content in geography education. The World in Spatial Terms refers geographic representations and technologies such as using maps to provide information through spatial perspective (Bednarz, Heffron, \& Huynh, 2013). Thus, it is possible to organize and analyze information about people, places, and environments in a spatial context. This is the rise of geospatial technologies for problem-solving since 1990s. The Uses of Geography helps to figure out the application of geography aspect of the time scales. Students should be able to interpret the past, the present, and the future ways to apply geographical phenomenon.

Hanson (2004) addressed exclusive features of geography and defined them as "the geographic advantage". She declared these advantages under four aspects. Two of these advantages specifically highlight spatial and temporal perception to promote geographical literacy. These are:

Geography recognizes the importance of spatial variability. Geography offers unique methodologies for investigating the way phenomena vary with location and explaining the placedependency of processes. Geography integrates spatial and temporal analysis. With its focus on spatial variability, geography offers unique techniques for integrating the analysis of variation over time with analysis of variation over space. Many other disciplines have focused on analysis 
of temporal variability without attention to the spatial dimension. (Bednarz, Heffron, and Huynh, 2013, p.20)

Spatial and temporal thinking skills are benefitted for analyzing geographic information. Students should "Find and describe spatial and temporal patterns in data, or find data that matches a pattern, to help solve a problem or answer a question" (Bednarz, Heffron, and Huynh, 2013, p.25). Spatial questions encourage students using variety of tools of representation (Jo, Bednarz \& Metoyer, 2010). Students should acquire geographic analytical perspectives, ranging from critical approaches to spatial and temporal thinking via geospatial technologies (Klein, Pawson, Solem \& Ray, 2014).

The National Research Council [NRC] (2006) claims that students should be able to:

(1) assess the quality of spatial data such as accuracy and reliability based on their source, (2) use a spatial rationale as a way of thinking to construct, articulate, and defend a line of reasoning in solving problems and answering questions, and (3) evaluate the validity of arguments or explanations based on spatial information. (Kim \& Bednarz, 2013a, p.351).

In parallel to NRC, Geographic Information System (GIS) learning indicates three components of critical spatial thinking. These are; evaluating data reliability, exercising spatial reasoning, and assessing problem-solving validity (Kim \& Bednarz, 2013a).

Turkish Social Studies Curriculum also suggests spatial thinking and declares:

To help students develop their ability to explain the interaction between humans and environment by learning about the general geographical features of the world and improve their spatial perception skills (Ministry of National Education [MoNE], 2018b, p.8).

Based on the nature of geography education, systematic structure of environmental issues and phenomenon play an important role. Systems thinking is explicitly intended learning outcomes for science courses around the world (Cox, Elen \& Steegen, 2019; Next Generation Science Standards [NGSS], 2013; NRC, 2012). Many researchers and educators define systems thinking as identifying and understanding various components and their relations in a system.

Geography courses are conducted on the use of models, causal diagrams and simulations to better understanding of systems in the field. Systems promote systems thinking in geography with different ways (Favier \& van der Schee, 2014). Geography is localization context of the components of the system or geographical pattern to figure out the systems in systems thinking (Cox, Elen \& Steegen, 2019). Geography also links people with natural/environmental systems (Hooghuis, van der Schee, van der Velde, Imants, \& Volman, 2014; International Geographical Union, 2016). Last, the scales are essential elements in systems thinking in geography. Even though systems are usually evaluated in macro scale such as migration and hunger, geographical scales are connected with different scales (i.e., ecological footprint).

Although the geography course is known as the course of secondary education, geography education actually takes its roots from the terms of skills in social studies and science lessons at primary education level. Knowledge of geography especially embedded in primary science education curriculum through earth science and physics topics. Therefore, it is necessary to underlie spatial and systems thinking 
skills required to gain geography literacy in primary and secondary school science lessons.

NGSS (2013) encourage students to build effective spatial scales and in-dept understanding regarding geoscientific topics depends on the middle school performance expectations in earth and space science. For example, the standards aim to provide students better imagination and comprehension about how processes change Earth's surface at time (i.e., slow plate motions, microscopic geochemical reactions, volcanoes, earthquakes) and how different components drive working of Earth's systems (i.e., wind, water-cycle, climate, gravity).

\section{Theoretical Framework}

Two models were considered when structuring the theoretical background of the study. The model of Elbay (2020) was used to clarify spatial thinking skills in the Turkish Primary Science Curriculum Framework (TPSCF). And, the model of Assaraf and Orion (2005) was also used to determine systems thinking skills in the text of the curriculum.

\section{Spatial Thinking}

As looking around, everybody recognizes a constant interaction between people and their environment. This awareness requires geography literacy a necessity for individuals. The implementation of geographic literacy and its applications in the field strongly influenced by spatial thinking skills (Ikhsan, Kurnianto, Apriyanto, Nurdin, 2018). Geographers are specifically interested in the term of space; therefore, they concern locations and places. At this point, spatial thinking has an important role in geography education because it provides an opportunity to visualize and analyze spatial relationships between objects such as location, region, distance, direction, shape and pattern.

Anthamatten (2010) presents spatial thinking considering a list of concepts which includes location, conditions, connections, comparison, aura, region, hierarchy, transition, analog, patterns and associations (Adapted from Gersmehl and Anthamatten, 2008; Gersmehl and Gersmehl, 2006).

NRC (2006) reported that three fundamental functions of spatial thinking in geography education. These are:

1. A descriptive function, capturing, preserving, and conveying the appearances of and relations among objects

2. An analytic function, enabling an understanding of the structure of objects; and

3. An inferential function, generating answers to questions about the evolution and function of objects. (p.33)

In parallel to the declaration of NRC, spatial thinking skills have been characterized by three subcategories into the model of Elbay (2020). These are; spatial description, spatial analysis, and spatial evaluation. 


\section{Spatial Description}

Spatial description in geography education includes twofold meaning. It provides information how living species act to meet their biological needs in natural environments. For example, action-behaviors of ants, bees, and bats in their daily life to survive (Öcal, 2007). Spatial description also refers as a cognitive map for better demonstration and representation of spatial environment in the mind. These definitions help to comprehend any data related to the position of an environment through reference points (Elbay, 2020). Thus, people are able to successfully memorize and define future actions relevant to spatial environment (Epstein, Patai, Julian \& Spiers, 2017). Spatially literate students adequately use vocabulary concerning spatial terms such as location, direction, and diffusion (Kim \& Bednarz, 2013b).

Based on spatial description thinking skill, students are expected to be able to successfully reading a map or calculating coordinate of an object, using spatial tools such as Geographic Information System (GIS), interpreting globes, diagrams, aerial images and illustrating some properties of a geographical area.

\section{Spatial Analysis}

Spatial analysis provides to learn about an environment through linking natural and human environmental features such as economic, physical and population related issues in an environment (Elbay, 2020). For example, the spread of disease (i.e., COVID-19 pandemic), natural disasters (i.e., earthquake, flood), trade, or immigration. Therefore, specific visual features help to analyze and explore locational features of an environment (Anselin, 1999; Öcal, 2014).

Spatial analysis is as a way of thinking to construct, articulate, and defend a line of reasoning in solving problems and answering questions through a spatial rationale (Kim, Bednarz, 2013a; NRC, 2006). Spatial data analysis focuses on exploration and confirmation about the spatial data. Therefore, spatial effects should be tested and spatial predictions made while benefiting from spatial analysis (Anselin, 1999). Field investigations, observations and past experiences help properly leading this process. For example, students are able to figure out earthquake triggers tsunami in the sea or ocean and high tides happens. Through thinking spatial analysis, students are able to estimate occurring huge waves causes flood and they anticipate that harmful effects of the flood over seaside settlements.

Depending on spatial analysis thinking skill, students are expected to be able to establish cause and effect relationship in a geoscientific issue (i.e., between space and natural environment, between space and human environment) and also determine facing geographical affairs by using obtained spatial data.

\section{Spatial Evaluation}

It is possible to investigate data about environmental features and convert the data to the knowledge through spatial evaluation. Thus, spatial evaluation offers sufficient information to people about the chosen environment. (Elbay, 2020). Also, interpretations the impacts on geological issues, such as climate change, on species (people, animals and plants) helps to protect environments and communities against environmental problems (Öcal, 2014). 
For example, spatial evaluation seeks out how to prevent people against natural disasters and to detect potential environmental disasters by considering economic and social effects. At this point, spatial evaluation thinking skill conducts with preliminary spatial analysis. If remembering the example mentioned above regarding spatial analysis, thinking about spatial evaluation requires reflecting on how the village can be protected against the tsunami, a natural disaster. Then, spatial evaluation thinking generates answers and making environmental arrangements such as building a breakwater or shifting the downtown far away the seaside to prevent village people from harmful effects of tsunami.

Students are expected to be able to make inference and find solution with regard to spatial data through benefitting from spatial evaluation thinking skill.

\section{Systems Thinking}

Globalization has brought global challenges with it. Dynamics of the system should be considered in order to find solutions for global problems. Many studies in different fields have sought how students come up with complex systems (Cox, Elen \& Steegen, 2019). These studies commonly point out the essential role of improving systems thinking abilities of students for being effective future decision makers in changing society (Senge, 2010; Sweeney \& Sterman, 2007).

Assaraf and Orion (2005) have developed a system thinking model relevant to hydro-cycle system. According to this model, eight components are related with systems thinking especially for environmental problem-solving situation.

These are;

1. The ability to identify the components of a system and processes within the system

2. The ability to identify relationships among the system's components

3. The ability to organize the systems' components and processes within a framework of relationships

4. The ability to make generalizations

5. The ability to identify dynamic relationships within the system

6. Understanding the hidden dimensions of the system

7. The ability to understand the cyclic nature of systems

8. Thinking temporally (Assaraf and Orion, p.523)

Few empirical studies have addressed the issue of promoting geography skills at primary school level. These studies specifically focus on Social Studies Curriculum (Ministry of National Education [MoNE], 2018b); however, there is a gap to seek on primary level science curriculum aspect of geographical skills.

As in other disciplines, the TPSCF was revised depends on constructivist approach and necessity requirements in 2018 (Ministry of National Education [MoNE], 2018a). Earth science related geographic phenomenon still takes an important place in the revised curriculum. However, it is concerned if the curriculum framework properly promotes geographical skills with this revision. 
Geographical skills can involve many different issues, but the particular interest of this study is to investigate the current position of TPSCF in terms of spatial and systems thinking skills in primary and secondary level Turkish science curriculum. These two thinking skills are decided to examine together because of their strong relationship with each other in geography education. For example, temporal thinking is considering both thinking abilities (Assaraf \& Orion, 2005; Cox, Elen \& Steegen, 2019)

The following research questions are addressed the research goals:

1. To what extent are spatial thinking skills represented 3 through 8 grades with respect to TPSCF?

2. To what extent are systems thinking skills represented 3 through 8 grades with respect to TPSCF?

\section{Methodology}

\section{Research Design}

This study was conducted in a qualitative research method. The qualitative data collection and data evaluation procedures were used to clarify the research questions. The findings were also interpreted by addressing and reviewing the main focus on the research.

The research was carried out by document analysis method of qualitative research design through content analysis (Creswell, 2012). Document analysis is the analysis of materials containing information about the subject of the research. It is possible to benefit from various documents such as journals, photographs, dairies, letters, official documents, autobiography or biography records in this analysis process (Creswell, 2013). The main objective of this research was to evaluate the integration of spatial and system thinking skills in the contexts of learning objectives of primary level Turkish science curriculum. Therefore, the research was built upon to investigate the latest version of TPSCF (MoNE, 2018a) through document analysis.

\section{Data Collection and Data Processing}

The study utilized a descriptive content analysis using data collected through the analysis of TPSCF. The latest version of science curriculum is evaluated through the lens of spatial and systems thinking skills with respect to the outlined framework. This data source was retrieved from the official website of Republic of Turkey Ministry of National Education (MoNE, 2018a).

\section{Data Analysis}

Both research questions involved qualitative data analysis. The data obtained in the research were analyzed by document analysis method. The analysis of the research was carried out according to the TPSCF as the primary source of the material. The analysis procedure of the study was twofold: 1) to identify sentencebased criterion to categorize the learning objectives in the science curriculum aspect of spatial thinking skills and systems thinking skills (the sentence-based criteria list is given in Table 1). 
For this purpose, each of the sentence was reviewed and compared until an agreement was reached with three experts in the field for inter-coder reliability). In comparisons the numbers of consensus and disagreement the reliability of calculated by using Miles and Huberman (1994) formula:

\section{Reliability $=$ Consensus $/$ (Consensus + Disagreement $) \times 100$}

The reliability of the research was found 93\%. If the result obtained with this formula is $90 \%$ and above, it is advocated that reliability is ensured.

Keywords were categorized under spatial and systems thinking titles according to the author and expert opinions. The learning objectives are coded into spatial thinking skills with the help of the key verbs in the sentences. For example, a learning objective consists of a verb such as "explain...", "compare...", "prepare...", or "realize..." refer to linking and interpreting the data with spatial thinking skills. Some examples from the learning objectives;

"Explain the structure of galaxies."

"Prepare a model that represents the movements of the Sun, Earth and Moon relative to each other."

"Realize that the shape of the Earth is like a sphere."

Anthamatten (2010) also provides specific example activities about spatial thinking skill in a table depends on early grade level geography standards from different states of the United States of America. Some of these standards are;

"Students demonstrate map skills by describing the absolute and relative locations of people, places, and environments" (California State Board of Education 1998, p.7).

"Compare and contrast basic land use in urban, suburban, and rural environments in California." (California State Board of Education 1998, p.7).

"Recognize how physical and human processes together shape places, i.e., the relationship between elevation and population density in a region or the characteristics of regions along the same latitude" (New Hampshire Department of Education 2006, p.29).

"Describe the relationships among location of resources, population distribution and economic activities (i.e., transportation, trade, communications)" (Illinois State Board of Education 1997, p.2).

The list of Cox, Steegen, Elen, and Leuven (2019) are also considered to decide sentence-based criteria for systems thinking skills. The list presents helpful frequently used key words as a hint to recognize systems thinking skills about the learning objective sentences in geography courses at high school level. They specifically highlight the words identify, relate, demonstrate, suggest, understand, examine when describing learning objectives relevant to systems thinking skills. For example;

"Students can identify the causes and solutions of unequal food supply and relate it to demographic evolutions and differences in prosperity." 
contexts of the learning objectives were explained much better on the tables. Below are the numbers and their referring systems thinking abilities;

1: Identify the Components of a System and Processes within the System

2: Identify Relationships among the System's Components

3: Organize the Systems' Components and Processes

4: Make Generalizations

5: Identify Dynamic Relationships within the System

6: Understanding the Hidden Dimensions of the System

7: Understand the Cyclic Nature of Systems

8: Thinking Temporally

\section{Findings}

The study reports on spatial and systems thinking skills considering 35 learning objectives from 14 different topics in primary and secondary level ( 3 to 8 grades) Turkish science curriculum. Following the learning objectives, the findings are presented in Table 2, 3, 4, 5, 6, and 7 for each grade level.

Table 2 shows the distributions of spatial and systems thinking skills in terms of $3^{\text {rd }}$ grade science curriculum learning objectives. In this analyzing process, "The Earth and The Universe" learning area related units and topics were considered. The learning objectives of this unit and topics were examined. Table 2 indicates that the learning objectives relevant to "Shape of the Earth" and "Structure of the Earth" topics of the "Getting to Know Our Planet" unit specifically focus on in favor of spatial description type of spatial thinking skill. This result probably was occurred because of the content and the grade level. Due to the fact that the unit specifically focus on the structure of the Earth, the learning objectives aim to provide description about the shape of the Earth and formation of its surface. Another reason education policy-makers often prefer to provide definition-based learning skills instead of to analyze and to evaluate the knowledge about the phenomenon for lower grade levels.

The learning objectives seem missing to figure out what happened in the process until the Earth takes its present shape. One other hand, systems thinking skills were limitedly embedded in the learning objectives in this unit. For the topic of "Shape of the Earth", only one learning objective provides systems thinking skill by mentioning about the role of the layers when constructing the shape of the Earth. However, the learning objective partly reflects identification of the component because there is no information about how layers contribute to formation of the shape of the Earth. When looking at the learning objectives of the topic of "Structure of the Earth", we encounter with similar problem. Although a learning objective presents a layer of air surrounds the Earth, it does not mention about the effects of the layer on the structural formation of the Earth. Another learning objective compare the areas of land and water, but it does not mention about how their distribution leads the structure of the Earth. All these situations cause the learning 
objectives remain incapable to promote understanding how systems and their components effect on the shape and structure of the Earth.

Table 2

Examination of Spatial and Systems Thinking Skills in Learning Objectives of $3^{\text {rd }}$ Grade Science Curriculum Framework

\begin{tabular}{|c|c|c|c|}
\hline Grade & Unit & Topi & \\
\hline $3^{\text {rd }}$ Grade & Getting to Know Our Planet & \multicolumn{2}{|c|}{ Shape of the Earth } \\
\hline Code & Learning Objective & $\begin{array}{l}\text { Spatial Thinking } \\
\text { Skills }\end{array}$ & $\begin{array}{l}\text { Systems Thinking } \\
\text { Skills }\end{array}$ \\
\hline F.3.1.1.1 & $\begin{array}{l}\text { Realize that the shape of the } \\
\text { Earth is like a sphere. } \\
\text { a. Past views on the shape of the } \\
\text { world are stated. }\end{array}$ & Spatial Description & $\mathrm{X}$ \\
\hline F.3.1.1.2 & $\begin{array}{l}\text { Prepare a model for the shape of } \\
\text { the Earth. }\end{array}$ & Spatial Description & $\mathrm{X}$ \\
\hline & $\begin{array}{l}\text { a. It is mentioned that the world } \\
\text { is made up of layers. }\end{array}$ & & 1 \\
\hline Grade & Unit & Topic & \\
\hline $3^{\text {rd }}$ Grade & Getting to Know Our Planet & Structure of $t$ & e Earth \\
\hline Code & Learning Objective & $\begin{array}{l}\text { Spatial Thinking } \\
\text { Skills }\end{array}$ & $\begin{array}{l}\text { Systems Thinking } \\
\text { Skills }\end{array}$ \\
\hline F.3.1.2.1 & $\begin{array}{l}\text { Understand that land and water } \\
\text { are located on the surface of the } \\
\text { world. }\end{array}$ & Spatial Description & $\mathrm{X}$ \\
\hline F.3.1.2.2 & $\begin{array}{l}\text { Explain that there is a layer of air } \\
\text { surrounding us in the Earth. }\end{array}$ & Spatial Description & 1 \\
\hline F.3.1.2.3 & $\begin{array}{l}\text { Compare the areas covered by } \\
\text { land and water on the Earth's } \\
\text { surface on the model. }\end{array}$ & Spatial Description & 2 \\
\hline
\end{tabular}

When looking at Table 3, the learning objectives concerning the unit of "Earth Crust and the Movements of Our Earth" in $4^{\text {th }}$ grade science curriculum was examined. The unit includes three types of spatial thinking skills both the topic of "Structure of the Earth Crust" and the topic of "The Movements of Our Earth". In this respect, it can be said that spatial thinking skills are highly reflected in learning objectives for both topics. Unfortunately, it is difficult to say same thing to enhance systems thinking skills for the first topic in the unit. There is limited clarification the relationship among the components of the Earth's structure (i.e., the minerals, the rocks, the crust, the mantle, and the core) except for one learning objective. The learning objectives seem still to provide some systems thinking skills, but they need more details. Until the $10^{\text {th }}$ grade geography course, the components of the Earth crust and its internal structure process are not emphasized. Therefore, it is very important to foster systems thinking skills especially aspect of the relationships among raw materials, fossils, and the layer of the Earth in this unit.

However, the second topic of the unit which is entitled "The Movements of Our Earth" help students to gain system thinking skills in various ways. The learning objectives provide different perspectives by mentioning about the movements of the 
Earth. First learning objective compares two different types of the movement of the Earth and highlights their relation with each other. This clarification refers second systems thinking ability which is about the relationships among the system's components. Based on the explanation of the same learning objective, the movements of the Earth are linked with daily life examples and a generalization is made. The second learning objective involves four systems thinking abilities through its explanations.

The learning objective clarifies what happens because of the movement of the Earth. The rotation of the Earth and the entanglement motion of the Earth are mentioned to identify how the events occurred. Thinking about the movements of the Earth their relation with each other is an opportunity for students to gain systems thinking skills aspect of first and second systems thinking abilities. Third explanation of the learning objective also promote better understanding of how rotation of the Earth effect on the position change of the Sun. It is evidence that dynamic relationship within the Solar System. Fourth and fifth explanations of the learning objective provide students to think temporally through predicting day/night and day/year time concepts depends on the motions/positions of the Earth and Sun.

Table 3

Examination of Spatial and Systems Thinking Skills in Learning Objectives of $4^{\text {th }}$ Grade Science Curriculum Framework

\begin{tabular}{|c|c|c|c|}
\hline Grade & Unit & Topic & \\
\hline $4^{\text {th }}$ Grade & $\begin{array}{l}\text { Earth Crust and the Movements of Our } \\
\text { Earth }\end{array}$ & \multicolumn{2}{|c|}{ Structure of the Earth Crust } \\
\hline Code & Learning Objective & $\begin{array}{l}\text { Spatial Thinking } \\
\text { Skills }\end{array}$ & $\begin{array}{c}\text { Systems } \\
\text { Thinking Skills } \\
\end{array}$ \\
\hline F.4.1.1.1 & $\begin{array}{l}\text { State that the layer of the Earth's } \\
\text { crust is made up of rocks. } \\
\text { a. It is not included in the } \\
\text { classification of rocks. }\end{array}$ & Spatial Description & $\mathrm{X}$ \\
\hline \multirow[t]{2}{*}{ F.4.1.1.2 } & $\begin{array}{l}\text { Relate rocks with minerals and } \\
\text { discusses the importance of rocks as } \\
\text { raw materials. }\end{array}$ & Spatial Evaluation & 3 \\
\hline & $\begin{array}{l}\text { a. It is referred to many rocks and } \\
\text { minerals in Turkey; gold, boron, } \\
\text { marble, lignite, copper, hard coal; } \\
\text { silver, etc. examples are given. }\end{array}$ & Spatial Analysis & \\
\hline F.4.1.1.3 & $\begin{array}{l}\text { Explain the formation of fossils. } \\
\text { a. Fossil types are not included. }\end{array}$ & Spatial Description & $\mathrm{X}$ \\
\hline Grade & Unit & \multicolumn{2}{|c|}{ Topic } \\
\hline $4^{\text {th }}$ Grade & $\begin{array}{l}\text { Earth Crust and the Movements of Our } \\
\text { Earth }\end{array}$ & \multicolumn{2}{|c|}{ The Movements of Our Earth } \\
\hline Code & Learning Objective & $\begin{array}{l}\text { Spatial Thinking } \\
\text { Skills }\end{array}$ & $\begin{array}{c}\text { Systems } \\
\text { Thinking Skills }\end{array}$ \\
\hline F.4.1.2.1 & $\begin{array}{l}\text { Explain the difference between the } \\
\text { rotation and entanglement } \\
\text { movements of the Earth. }\end{array}$ & Spatial Description & 2,4 \\
\hline
\end{tabular}




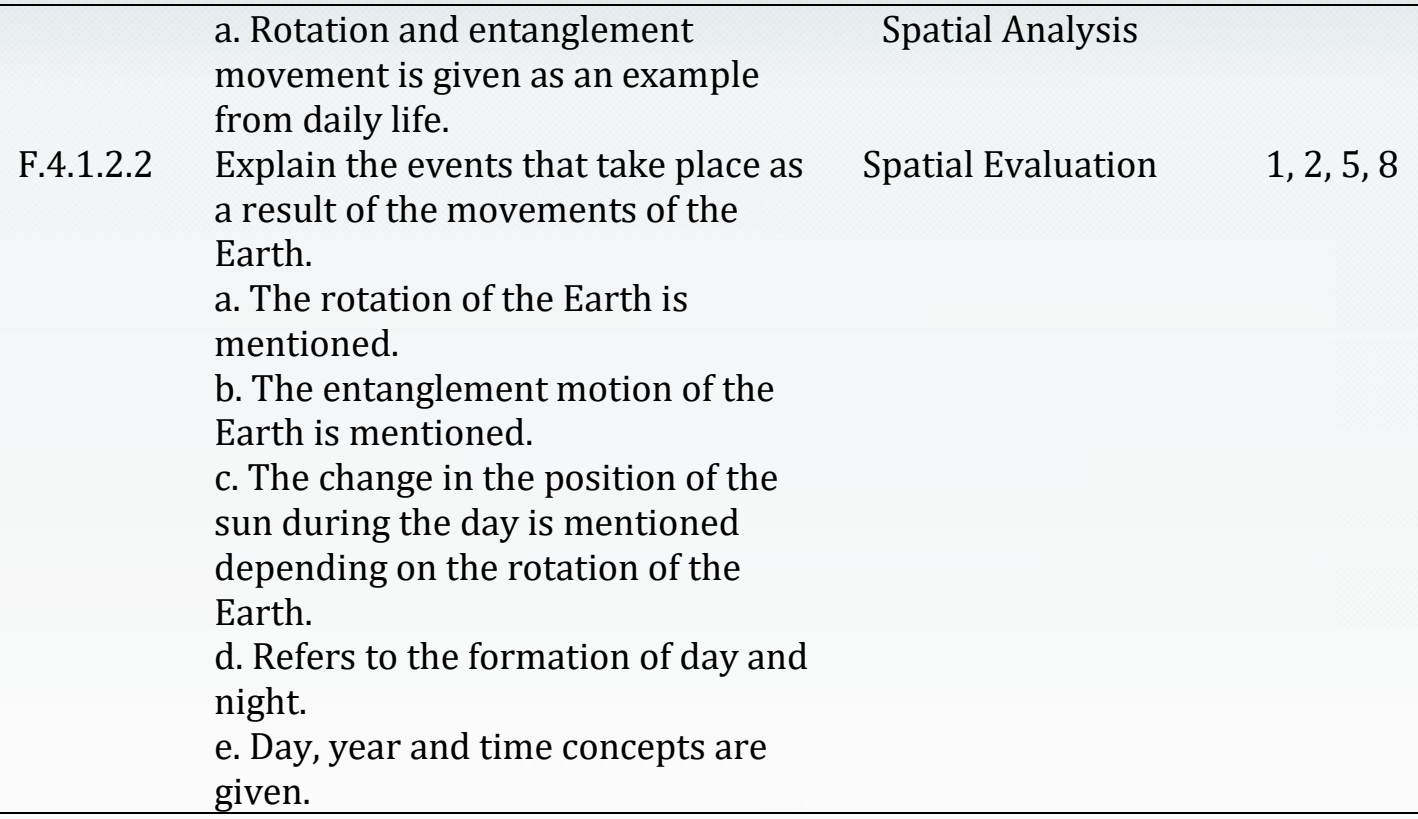

The learning objectives concerning the unit of "Sun, Earth, and Moon" were analyzed in relation to spatial and systems thinking skills in Table 4. The unit includes four topics. Spatial thinking skills gather around spatial description for the topic of "Structure and Properties of the Sun". The learning objectives focus on spatial description type of spatial thinking abilities since this topic points out the features of the Sun. While mentioning about the structure of the Sun, the learning objectives do not indicate how the Sun effects on the lives of our Earth and the living creatures in which we belong. Therefore, first topic of the unit should be reconsidered to gain students spatial systems thinking skills aspect of spatial analysis and spatial evaluation. There is no clarification relevant to systems thinking skills in the learning objectives for this topic.

For the topic of "Structure and Properties of the Moon", the learning objectives bring students in both spatial and systems thinking skills. The learning objectives describe the properties of the Moon and discuss about the link between the Moon and the living creatures. It is noticed that the lack of spatial evaluation skill in this topic. For example, the structural characteristics of the Moon could be evaluated in terms of travel and settlement. This is an essential issue because The Moon is not specifically mentioned in secondary level geography curriculum framework. For systems thinking skills, second learning objective indicates the opinions about living creatures to live on the moon. Thus, this discussion provides an opportunity to understand the concealed dimensions of the Moon and refers the sixth systems thinking ability.

When analyzing the topic "Movements and Phases of the Moon", the learning objectives focus on spatial description thinking skill to define types of the movements and phases of the Moon. Third explanation of the first learning objective involve spatial evaluation skill because the concept of the Moon was converted to time zone as a time scale. Both of the learning objectives also encourage students to 
think about systemic with various perspectives. For example, first learning objective involves first systems thinking ability by identifying rotation and entanglement movements of the moon. Second learning objective states second systems thinking ability to relate the phases of the Moon and the motion of the Moon around the Earth. In addition, students are able to recognize the cyclical nature of the Moon and relate this periodical movement and understand two main phases take one week (seventh \& eighth systems thinking abilities). Then, they are able to generalize and refers fourth systems thinking ability.

The last learning objective regarding the topic of "Sun, Earth and Moon", which has the same name as the unit, offers the spatial description thinking skill. The learning objective indicates the relative positions and directions of the Sun, Earth and Moon to each other through systems thinking features (first systems thinking ability). Thus, it provides better understanding of Solar System and the positional relationship among the components of the system (second systems thinking ability). These thinking skills should be gained deeper in $5^{\text {th }}$ grade because Sun, Earth, and Moon are limitedly emphasized under the unit of "Natural Systems" in 9 $9^{\text {th }}$ grade geography curriculum.

Table 4

Examination of Spatial and Systems Thinking Skills in Learning Objectives of $5^{\text {th }}$ Grade Science Curriculum Framework

\begin{tabular}{|c|c|c|c|}
\hline Grade & Unit & Topic & \\
\hline $5^{\text {th }}$ Grade & Sun, Earth and Moon & Structure and Pro & erties of the Sun \\
\hline Code & Learning Objective & $\begin{array}{c}\text { Spatial Thinking } \\
\text { Skills }\end{array}$ & $\begin{array}{c}\text { Systems Thinking } \\
\text { Skills }\end{array}$ \\
\hline F.5.1.1.1 & $\begin{array}{l}\text { Explain the properties of the } \\
\text { Sun. } \\
\text { a. The geometric shape of the } \\
\text { Sun is mentioned. } \\
\text { b. It is mentioned that the Sun is } \\
\text { made up of layers like the Earth, } \\
\text { but the structure of the layers. } \\
\text { c. It is stated that the Sun makes } \\
\text { a rotational motion. }\end{array}$ & Spatial Description & $\mathrm{X}$ \\
\hline F.5.1.1.2 & $\begin{array}{l}\text { Prepare a model to compare the } \\
\text { size of the Sun with the size of } \\
\text { the Earth. }\end{array}$ & Spatial Description & $\mathrm{X}$ \\
\hline Grade & Unit & Topic & \\
\hline $5^{\text {th }}$ Grade & Sun, Earth and Moon & \multicolumn{2}{|c|}{ Structure and Properties of the Moon } \\
\hline Code & Learning Objective & $\begin{array}{c}\text { Spatial Thinking } \\
\text { Skills }\end{array}$ & $\begin{array}{c}\text { Systems Thinking } \\
\text { Skills }\end{array}$ \\
\hline F.5.1.2.1 & $\begin{array}{l}\text { Explain the properties of the } \\
\text { Moon. } \\
\text { a. The size of the moon is } \\
\text { specified. } \\
\text { b. The geometric shape of the } \\
\text { Moon is mentioned. }\end{array}$ & Spatial Description & $\mathrm{X}$ \\
\hline
\end{tabular}


c. Information is given about the surface structure of the moon.

d. The atmosphere of the Moon is mentioned.

F.5.1.2.2 Discuss the ideas produced for living creatures to live on the

Spatial Analysis

6 moon.

\begin{tabular}{|c|c|c|c|}
\hline Grade & Unit & Topic & \\
\hline $5^{\text {th }}$ Grade & Sun, Earth and Moon & Movements and Phase & of the Moon \\
\hline Code & Learning Objective & $\begin{array}{c}\text { Spatial Thinking } \\
\text { Skills }\end{array}$ & $\begin{array}{c}\text { Systems Thinking } \\
\text { Skills }\end{array}$ \\
\hline F.5.1.3.1 & $\begin{array}{l}\text { Explain the rotation and } \\
\text { entanglement movements of the } \\
\text { moon. } \\
\text { a. It is stated that the Moon } \\
\text { makes a rotational movement. } \\
\text { b. It is stated that the Moon } \\
\text { moves around. } \\
\text { c. The concept of the moon is } \\
\text { mentioned as a time zone. }\end{array}$ & Spatial Description & 1,8 \\
\hline F.5.1.3.2 & $\begin{array}{l}\text { Explain the relationship } \\
\text { between the phases of the Moon } \\
\text { and the motion of the Moon } \\
\text { around the Earth. } \\
\text { a. The difference(s) between the } \\
\text { main and intermediate phases } \\
\text { of the moon are indicated. } \\
\text { b. The names of the phases of } \\
\text { the Moon are indicated in the } \\
\text { order to occur. } \\
\text { c. It is stated that the period } \\
\text { between the two main phases of } \\
\text { the Moon is one week. }\end{array}$ & Spatial Description & $2,4,7,8$ \\
\hline Grade & Unit & \multicolumn{2}{|l|}{ Topic } \\
\hline $5^{\text {th }}$ Grade & Sun, Earth and Moon & \multicolumn{2}{|c|}{ Sun, Earth and Moon } \\
\hline Code & Learning Objective & $\begin{array}{c}\text { Spatial Thinking } \\
\text { Skills }\end{array}$ & $\begin{array}{l}\text { Systems Thinking } \\
\text { Skills }\end{array}$ \\
\hline F.5.1.4.1 & $\begin{array}{l}\text { Prepare a model that represents } \\
\text { the movements of the Sun, Earth } \\
\text { and Moon relative to each other. } \\
\text { a. The direction of the Moon } \\
\text { orbiting the Earth is indicated. } \\
\text { b. The direction of the Earth } \\
\text { around the Sun is indicated. } \\
\text { c. It is stated that when viewed } \\
\text { from the Earth, the same face of } \\
\text { the Moon is always seen. }\end{array}$ & Spatial Description & 2 \\
\hline
\end{tabular}

Table 5 shows that the learning objectives about the unit of "Solar System and Eclipses" in $6^{\text {th }}$ grade science curriculum supports spatial thinking skills and 
systems thinking skills. According to the topic of "Solar System", the learning objectives provide an opportunity to compare the planets in the solar system aspect of their properties and prepare a solar system model considering their distance from the Sun. In this regard, spatial thinking skills are gained through spatial description in terms of second and third systems thinking abilities. When looking at the topic of "Solar and Lunar Eclipses", the learning objectives encourage students to enhance both spatial thinking and systems thinking skills. Spatial thinking skills are presented through spatial description by creating Solar and Moon eclipse models and spatial evaluation by predicting how eclipses occur. However, the learning objectives need to be developed in terms of spatial analysis. There is no clarification about how eclipses effect on human environment. On the other hand, the explanations of the learning objectives emphasize temporal thinking relevant to how the eclipses occurs and this knowledge supports systems thinking skill in terms of fifth and eighth systems thinking abilities.

Table 5

Examination of Spatial and Systems Thinking Skills in Learning Objectives of $6^{\text {th }}$ Grade Science Curriculum Framework

\begin{tabular}{|c|c|c|c|}
\hline Grade & Unit & \multirow{2}{*}{\multicolumn{2}{|c|}{$\begin{array}{c}\text { Topic } \\
\text { Solar System }\end{array}$}} \\
\hline $6^{\text {th }}$ Grade & Solar System and Eclipses & & \\
\hline Code & Learning Objective & $\begin{array}{c}\text { Spatial Thinking } \\
\text { Skills }\end{array}$ & $\begin{array}{l}\text { Systems Thinking } \\
\text { Skills }\end{array}$ \\
\hline F.6.1.1.1 & $\begin{array}{l}\text { Compare the planets in the solar } \\
\text { system with each other. } \\
\text { a. Basic properties of the planets } \\
\text { (terrestrial, gaseous, inner } \\
\text { planet, exoplanet) are mentioned. } \\
\text { b. It is mentioned that the planets } \\
\text { have moons. } \\
\text { c. The sizes of the planets are } \\
\text { mentioned spatially. }\end{array}$ & Spatial Description & 2 \\
\hline F.6.1.1.2 & $\begin{array}{l}\text { Create a model by listing the } \\
\text { planets in the solar system } \\
\text { according to their proximity to } \\
\text { the Sun. }\end{array}$ & Spatial Description & 3 \\
\hline Grade & Unit & \multicolumn{2}{|c|}{ Topic } \\
\hline $6^{\text {th }}$ Grade & Solar System and Eclipses & \multicolumn{2}{|c|}{ Solar and Lunar Eclipses } \\
\hline Code & Learning Objective & $\begin{array}{c}\text { Spatial Thinking } \\
\text { Skills }\end{array}$ & $\begin{array}{c}\text { Systems Thinking } \\
\text { Skills } \\
\end{array}$ \\
\hline F.6.1.2.1. & $\begin{array}{l}\text { Predict how a solar eclipse } \\
\text { occurs. } \\
\text { a. The phase of the Moon during } \\
\text { the solar eclipse is mentioned. } \\
\text { b. It is mentioned that there is no } \\
\text { solar eclipse every month. }\end{array}$ & Spatial Evaluation & 5,8 \\
\hline F.6.1.2.2 & $\begin{array}{l}\text { Predict how a lunar eclipse } \\
\text { occurs. } \\
\text { a. The phase of the moon during } \\
\text { the lunar eclipse is mentioned. }\end{array}$ & Spatial Evaluation & 5,8 \\
\hline
\end{tabular}


b. It is mentioned that lunar eclipse is not every month.

F.6.1.2.3 Create a model representing the Sun and Lunar eclipse.

Table 6 represents the distributions of spatial and systems thinking skills in $7^{\text {th }}$ grade science curriculum learning objectives. Based on the unit of "Solar System and Beyond", the topic of "Space Researches" and "Beyond Solar System: Celestial Bodies" were investigated. The learning objectives of the topic of "Space Researches" involves three types of spatial thinking skills. Although there is limited clarification, space technologies express the equipment such as satellites, spacecraft and these are related with their rotations, locations, and direction.

First learning objective refers spatial description thinking skill with this feature. Second explanation of this learning objective also foster spatial evaluation skill to indicate duties of Turkish satellites. Even though the explanation excludes any details, these satellites could be evaluated an opportunity for Turkey aspect of better communications, a stronger political stance, economic power and similar issues. Therefore, this explanation of the learning objective encourages students to gain spatial evaluation skill.

The second learning objective indicates the important impact of space pollution on space environment and human population. Regarding this feature, this learning objective also promotes spatial evaluation skill. The fourth and sixth learning objectives portray the telescope and support spatial description skill. The fifth learning objective is to improve both spatial analysis and spatial evaluation skills due to the explanations of it highlights astronomy and its relation with telescope and cultural issues. This learning objective encourage gaining spatial evaluation skill by emphasizing the important effect of invitation of telescope on the development of astronomy. The second explanation of the learning objective provide to gain spatial evaluation skill to mention about how Western astronomers and TurkishIslamic astronomers contribute to astronomy. The first explanation of the learning objective also involves spatial analysis because it explains how best location is decided to settle in observatory places.

Systems thinking abilities are partially referred when analyzing the learning objectives of first unit. Systems thinking skill reflect to the first learning objective describing the components of space technology. Thus, the learning objective provide better comprehension by describing space through space technologies and refers first systems thinking ability. The third and fourth learning objectives involve second systems thinking ability. The third learning objective relates technology and space exploration while describing the space system. The fourth learning objective links telescope and light pollution observing space. When looking at the second learning objective, it is recognized that space pollution has been occurring. This learning objective provide an opportunity to think possible consequences over space pollution. It refers sixth systems thinking ability with this perspective because people often unaware of space pollution and its reasons. 
The learning objectives of the topic of "Beyond Solar System: Celestial Bodies" include spatial description thinking skill. These learning objectives define star, galaxy, and universe through mentioning about their formation and structure. In addition, the third learning objective describes the structure of the galaxy in general and then gives The Milky Way and Andromeda galaxies as specific example for providing better comprehension and analysis of the galaxy system. For this feature, this learning objective involves spatial analysis type of spatial thinking skills. While mentioning about the galaxies, it could have explained the formation process of a galaxy. Thus, systems thinking abilities such as thinking temporally, identifying dynamic relation among the components of the galaxy system could have improved through the learning objective. It is seen that only one learning objective provides eighth systems thinking ability by linking temporal thinking with light years. One other hand, discussing about Big Bang theory could have motivated students think about galaxy system and encourage them to gain systems thinking abilities.

Table 6

Examination of Spatial and Systems Thinking Skills in Learning Objectives of $7^{\text {th }}$ Grade Science Curriculum Framework

\begin{tabular}{|c|c|c|c|}
\hline Grade & Unit & \multicolumn{2}{|c|}{ Topic } \\
\hline $7^{\text {th }}$ Grade & Solar System and Beyond & Space Re & earches \\
\hline Code & Learning Objective & $\begin{array}{c}\text { Spatial Thinking } \\
\text { Skills }\end{array}$ & $\begin{array}{l}\text { Systems Thinking } \\
\text { Skills }\end{array}$ \\
\hline F.7.1.1.1 & $\begin{array}{l}\text { Explain space technologies. } \\
\text { a. Artificial satellites are } \\
\text { mentioned. } \\
\text { b. It is mentioned that Turkey } \\
\text { launched by satellites to space } \\
\text { and their duties. }\end{array}$ & Spatial Description & 1 \\
\hline F.7.1.1.2 & $\begin{array}{l}\text { State the causes of space } \\
\text { pollution and predict the } \\
\text { possible consequences of this } \\
\text { pollution. }\end{array}$ & Spatial Evaluation & 6 \\
\hline F.7.1.1.3 & $\begin{array}{l}\text { Explain the relationship } \\
\text { between technology and space } \\
\text { exploration. }\end{array}$ & & 2 \\
\hline F.7.1.1.4. & $\begin{array}{l}\text { Explain the structure of the } \\
\text { telescope and what it does. } \\
\text { a. The types of telescopes are } \\
\text { mentioned. } \\
\text { b. Light pollution is mentioned. }\end{array}$ & Spatial Description & 2 \\
\hline F.7.1.1.5 & $\begin{array}{l}\text { Infer the importance of the } \\
\text { telescope in the development of } \\
\text { astronomy. } \\
\text { a. The selection of the } \\
\text { observatory places and the } \\
\text { conditions of these places are } \\
\text { mentioned. } \\
\text { b. The contributions of Western } \\
\text { astronomers and Turkish- }\end{array}$ & $\begin{array}{l}\text { Spatial Evaluation } \\
\text { Spatial Analysis }\end{array}$ & $\mathrm{X}$ \\
\hline
\end{tabular}


Islamic astronomers are mentioned.

\begin{tabular}{|c|c|c|c|}
\hline F.7.1.1.6 & $\begin{array}{l}\text { Prepare a simple telescope } \\
\text { model and present it. }\end{array}$ & Spatial Description & $\mathrm{X}$ \\
\hline Grade & Unit & \multicolumn{2}{|c|}{ Topic } \\
\hline $7^{\text {th }}$ Grade & Solar System and Beyond & \multicolumn{2}{|c|}{ Beyond Solar System: Celestial Bodies } \\
\hline Code & Learning Objective & $\begin{array}{l}\text { Spatial Thinking } \\
\text { Skills }\end{array}$ & $\begin{array}{c}\text { Systems Thinking } \\
\text { Skills }\end{array}$ \\
\hline F.7.1.2.1 & $\begin{array}{l}\text { Recognize the star formation } \\
\text { process. } \\
\text { a. The concept of nebula is } \\
\text { mentioned. } \\
\text { b. Examples of nebulae are } \\
\text { given. } \\
\text { c. The concept of black hole is }\end{array}$ & Spatial Description & $\mathrm{X}$ \\
\hline
\end{tabular}

F.7.1.2.2 Explain the concept of star.

a. Star types are mentioned.

b. Constellations, which are the names of the star groups seen as viewed from Earth, are mentioned.

c. It is mentioned that the distance between celestial bodies is stated in light years.

F.7.1.2.3 Explain the structure of galaxies.

Spatial Description

a. Galaxy types are mentioned.

b. The Milky Way and

Andromeda galaxies are mentioned as examples of galaxies.

F.7.1.2.4 Explain the concept of universe. Spatial Description $\mathrm{X}$

In Table 7, the learning objectives partially encourage spatial thinking skills and systems thinking skills. The learning objective of the topic of "The Formation of the Seasons" seems to present spatial thinking skills with spatial description and spatial evaluation. The learning objective of this topic involve spatial evaluation to require students predicting how seasons occur. When looking at the explanations of the learning objective, spatial description thinking skill is also promoted by mentioning about the rotational axis of the Earth. But spatial thinking skill is still insufficient in terms of gaining spatial analysis. For example, there is no definition about how seasons and climate happen. Furthermore, the difference between the meaning of seasons and climate should be pointed out with a learning objective. Since, climate is average of meteorological events such as temperature, humidity, air pressure, wind, precipitation, precipitation pattern observed over a long period of time. However, seasons occur because of the axis of the Earth when rotating around the Sun. Although climate change is mentioned in the introduction part of the unit, this situation is not reflected in the learning objectives. 
From the perspective of systems thinking abilities, the learning objective of the first topic includes first and second systems thinking abilities. The second explanation emphasizes the relationship between the rotational axis of the Earth and its rotation around the Sun. Thus, the explanation refers to second systems thinking ability. The third explanation of the topic also involves second systems thinking ability to relate light energy and seasonal formation.

Table 7

Examination of Spatial and Systems Thinking Skills in Learning Objectives of $8^{\text {th }}$ Grade Science Curriculum Framework

\begin{tabular}{|c|c|c|c|}
\hline Grade & Unit & \multicolumn{2}{|c|}{ Topic } \\
\hline $8^{\text {th }}$ Grade & Seasons and Climate & \multicolumn{2}{|c|}{ The Formation of the Seasons } \\
\hline Code & Learning Objective & $\begin{array}{l}\text { Spatial Thinking } \\
\text { Skills }\end{array}$ & $\begin{array}{l}\text { System Thinking } \\
\text { Skills }\end{array}$ \\
\hline F.8.1.1.1 & $\begin{array}{l}\text { Predict the formation of the } \\
\text { seasons. } \\
\text { a. It is mentioned that the Earth } \\
\text { is the axis of rotation. } \\
\text { b. The relationship between the } \\
\text { rotational axis of the Earth and } \\
\text { its rotation around the Sun is } \\
\text { mentioned. } \\
\text { c. The effect of the amount of } \\
\text { energy per unit surface of light } \\
\text { on the seasons is mentioned. }\end{array}$ & $\begin{array}{l}\text { Spatial Evaluation } \\
\text { Spatial Description } \\
\text { Spatial Description } \\
\text { Spatial Description }\end{array}$ & 2 \\
\hline Grade & Unit & \multicolumn{2}{|c|}{ Topic } \\
\hline $8^{\text {th }}$ Grade & Seasons and Climate & \multicolumn{2}{|c|}{ Climate and Air Movements } \\
\hline Code & Learning Objective & $\begin{array}{l}\text { Spatial Thinking } \\
\text { Skills }\end{array}$ & $\begin{array}{l}\text { System Thinking } \\
\text { Skills }\end{array}$ \\
\hline F.8.1.2.1 & $\begin{array}{l}\text { Explain the difference between } \\
\text { climate and weather events. }\end{array}$ & Spatial Description & $\mathrm{X}$ \\
\hline F.8.1.2.2 & $\begin{array}{l}\text { Know climate science } \\
\text { (climatology) is a branch of } \\
\text { science and climate scientist is } \\
\text { named climatologist. }\end{array}$ & $\mathrm{X}$ & $\mathrm{X}$ \\
\hline
\end{tabular}

A summary table below provides the distribution of spatial and systems thinking skills categories across different grade levels (see Table 8). The results show that spatial thinking skill is favor of spatial description type of it at primary and secondary school level science curriculum. On the other hand, systems thinking abilities often gather around identifying relationships among the system's components (9 times), temporal thinking over the system's components (6 times), and identifying the components of a system and processes within the system (5 times). 
Table 8

Spatial and Systems Thinking Skills Distributions across the Learning Objectives for Each Grade Level

\begin{tabular}{lccccccccccc}
\hline Grade Level & \multicolumn{3}{c}{ Spatial Thinking Skills } & \multicolumn{8}{c}{ Systems Thinking Skills } \\
& SD & SA & SE & $1^{\text {st }}$ & $2^{\text {nd }}$ & $3^{\text {rd }}$ & $4^{\text {th }}$ & $5^{\text {th }}$ & $6^{\text {th }}$ & $7^{\text {th }}$ & $8^{\text {th }}$ \\
\hline $3^{\text {rd }}$ Grade & 5 & 0 & 0 & 2 & 1 & & & & & & \\
\hline $4^{\text {th }}$ Grade & 3 & 2 & 2 & 1 & 2 & 1 & 1 & 1 & & & 1 \\
\hline $5^{\text {th }}$ Grade & 4 & 1 & 1 & 1 & 2 & & 1 & & 1 & 1 & 2 \\
\hline $6^{\text {th }}$ Grade & 3 & 0 & 2 & & 1 & 1 & & 2 & & \\
\hline $7^{\text {th }}$ Grade & 7 & 3 & 2 & 1 & 2 & & & 1 & & 1 \\
\hline $8^{\text {th }}$ Grade & 4 & 0 & 1 & & 1 & & & & \\
\hline Total & 26 & 6 & 8 & 5 & 9 & 2 & 2 & 3 & 2 & 1 & 6 \\
\hline
\end{tabular}

\section{Result and Discussion}

This study revealed how spatial and systems thinking skills embedded in the TPSCF. It is investigated to what extent spatial and systems thinking skills according to grade level and distributed geography related units in Turkish science curriculum. The analyzed data reflected the weight of these skills over earth science and some physics (i.e., astronomy) related learning objectives from $3^{\text {rd }}$ grade to $8^{\text {th }}$ grade science curriculum. The results exhibited that spatial and systems thinking skills are partially acquired for each grade level. Some units should be reconsidered aspect of improving these thinking skills. There is insufficient information and definition to figure out these skills into the content of the learning objectives especially for $3^{\text {rd }}$ and $8^{\text {th }}$ grade science curriculum.

According to the analysis of "Getting to Know Our Planet" unit in the $3^{\text {rd }}$ grade, the learning objectives were entirely associated with spatial description ( 5 times). For this unit there is no evidence of systems thinking skills being acquired from the learning objectives. It is understandable the learning objectives specifically focus on spatial thinking skills and these are mainly coming from spatial description thinking because of the content of the unit. The topics of the unit focus on to describe shape and structure of the Earth. Therefore, better visualization is required and some of the learning objectives provide visualization by benefitting from the Earth models. It is expected that teachers benefit from models, multimedia tools, cognitive maps and similar materials as Kinzel and Wright, (2008) claimed their study regarding using geovisualizations in geography education.

Analyses of the $4^{\text {th }}$ grade learning objectives from the unit of "Earth Crust and the Movements of Our Earth" showed that the learning objectives represents three types of spatial thinking skills which were entitled spatial description (3 times), spatial analysis ( 2 times), and spatial evaluation ( 2 times). This time, it seemed that the learning objectives also reflected various systems thinking abilities. Among these, the ability to identify the relationships among the system's components (second ability on the list) is the most prominent ability with three times determined. In addition, the learning objectives provide to gain systems thinking abilities through identifying the different movements of the Earth (rotation and entanglement) and processes of how day and night occurs and making 
generalizations concerning the movement of the Earth, and then identifying dynamic relationships of the movement of the Earth and thinking temporally for the concepts of day and year. However, it can be recognized that almost all of the abilities take place the learning objectives under the second topic of the unit. The first topic is about structure of the Earth crust and the learning objectives are insufficient to gain students systems thinking abilities. Only one systems thinking ability was determined; therefore, this topic should be reconsidered aspect of systems thinking skills integration with the learning objectives.

When analyzing the $5^{\text {th }}$ grade learning objectives in the unit of "Sun, Earth and Moon", it is recognized that spatial thinking skills mostly reflected with spatial description thinking skill (4 times), spatial analysis (1 time), and spatial evaluation (1 time). The unit mainly purposes to define structure and properties of the Sun, the Earth, and the Moon. This is the causal result of the weight of spatial description. On the other hand, the topic of "Movements and Phases of the Moon" exhibits enriched systems thinking abilities especially for the cyclic nature of the Moon through its phases. This topic reflects the relationship of the movements of the Earth and the Moon and also emphasizes the periodic cycle of the Moon phases. Thus, students are encouraged to comprehend the roles of movements of the Earth and the Moon and make generalization through temporal thinking about lunar phase.

According to the data analysis of the unit of "Solar System and Eclipses" in $6^{\text {th }}$ grade curriculum, it should be separately evaluated spatial and systems thinking skills for each topic. Spatial thinking abilities are mostly embedded in the learning objectives as spatial description ( 3 times) and spatial evaluation ( 2 times). The analysis result also highlights there is no evidence that spatial analysis type of spatial thinking skills. Since first topic of the unit indicates the location and distance of the planets in the solar system, the learning objectives focuses on spatial description thinking skill. By the way, the learning objectives especially for the second topic which is related with solar and lunar eclipses trigger systems thinking skill aspect of dynamic relationship the movement of the Sun and the Moon (the fifth systems thinking ability), and thinking about temporal thinking considering the positions of the Sun and the Moon (the eighth systems thinking ability).

The learning objectives of the unit of "Solar System and Beyond" in $7^{\text {th }}$ grade curriculum promote to gain various spatial and systems thinking skills. Spatial description (7 times) is again prominent thinking skill type of spatial thinking as being previously analyzed learning objectives in different grade levels and the units. Many researchers and educators strongly suggest using map-reading activities to provide skills in favor of spatial thinking (Huang, Qu, \& Chen, 2020; Merç, 2011).

Although the unit is centered around space researches, it has remained limited only by mentioning the relationship among some components within the space system aspect of systems thinking abilities. Such as satellites, space travel and similar issues could be considered and integrated the learning goals. Thus, more systems thinking abilities can be gained relevant to thinking about hidden dimensions of space system, thinking about temporal changes in space technology depends on inventions, explorations and so on. 
Spatial thinking skills mostly involve as spatial description (4 times) in the learning objectives of the unit of "Seasons and Climate" in $8^{\text {th }}$ grade curriculum. Contrary to the analyze results of spatial thinking skills, systems thinking abilities are insufficiently embedded in the learning objectives. However, systems thinking skills could be gained effectively if the unit deeply related to the role of climate and seasons over people such as global warming. The grade level is also proper to think and discuss about climate and its effects on lively life.

In his study, Elbay (2020) asserts that there is not a hierarchical structure among spatial thinking skills as respectively mentioned spatial description, spatial analysis, and spatial evaluation. This result is implicitly supported analyzing the unit of "Solar System and Eclipses" in $6^{\text {th }}$ grade science curriculum and the unit of "Seasons and Climate" in $8^{\text {th }}$ grade science curriculum. When considering the distribution of spatial thinking skill types for both units, it is recognized that the learning objectives skip spatial analysis skill.

When looking at all the identified thinking skills, the findings highlight spatial description (26 of 40) is the most benefitted spatial thinking skill and the ability to identify relationships among the system's components (8 of 27) is the most benefitted systems thinking ability. It could be inferred TPSCF mostly provide spatial thinking skills considering representations and vocabulary (i.e., location, direction, definition) from this result. It could be also inferred TPSCF mostly reflect systems thinking skills with focusing on the relationships among the system's components. The emergence of such a result is not surprising, as the acquisition of spatial data and concepts in early grade levels is prioritized.

Overall, the learning objectives of $4^{\text {th }}$ and $7^{\text {th }}$ grade seem to be generally enriched and sufficient in terms of spatial thinking skills. The results of the analysis also emphasize that the learning objectives of $4^{\text {th }}$ and $7^{\text {th }}$ grade successfully provided various categories of systems thinking abilities (see Table 8).

\section{Suggestions}

The following suggestions could be helpful to enhance TPSCF relevant to spatial and systems thinking skills.

1. The study eventually suggests that some of the analyzed units of TPSCF should be reconsidered aspect of spatial and systems thinking skills. For example, although $3^{\text {rd }}$ grade topics are very similar to topics of geography lesson in terms of the content, the learning objectives seem insufficient to encourage students to gain spatial and systems thinking skills. However, concepts such as land, water, and air layers which are expressed in the learning objectives can be taught by taking into account as leading components of oceans and continents, when explaining the shape and structure of the Earth. However, concepts such as land, water, and air layers which are expressed in the learning objectives can be taught by taking into account as leading components of oceans and continents, while relating with the shape and structure of the Earth.

2. It is difficult to anticipate whether the learning objectives encourage to develop spatial or systems thinking abilities for some of the learning objectives 
when reading the context. At this point, the learning objectives should be clarified desired goals. For example, the learning objective of "Create a model representing the Sun and Lunar eclipse." in $6^{\text {th }}$ grade, and the learning objective of "Explain the concept of universe." in $7^{\text {th }}$ grade should be clarified with additional explanations deciding whether they reflect any types or spatial thinking skills and systems thinking skills.

3. Moreover, the findings suggest that spatial analysis skill should be more integrated into the learning objectives. In terms of systems thinking skills, the insufficiency of learning objectives is felt especially at the $8^{\text {th }}$ grade level. For example, the learning objectives of "Seasons and Climate" unit should be reconsidered relevant to climate change (global warming). The possible lack of attention in understanding cycling nature of the climate without natural cycles could cause learning difficulties about global warming. It is not mentioned about natural cycles such as the carbon cycle (i.e., the greenhouse effect), the water cycle, and the oxygen cycle, and nitrogen cycle until $11^{\text {th }}$ grade geography course.

4. It is shown that higher level spatial and systems thinking abilities are limited and this situation is not related with in some of the grade levels. As proof of this, it is seen that the number of learning objectives related with spatial analysis and spatial evaluation is much less than spatial description. The learning objectives should be reorganized supporting provocative, and inquiry-based thinking questions to solve this problem. For example, the topic of "Movements and Phases of the Moon" in $5^{\text {th }}$ grade should be reconsidered and enriched aspect of inquiry-based learning. In this topic, it can be emphasized how the movements of the Earth and the Moon affect the tidal events on the Earth. Surface. At this point, the learning objective could be linked with phases of the Moon and gravity. Thus, spatial and systems thinking abilities strength through rewritten learning objectives. Thus, spatial and systemic thinking abilities are acquired through rewritten learning objectives.

5. Digital content and software programs should be more used such as simulations, smart graphs and augmented reality for better understanding of the temporal changes and the relationships among the system components. At this point, it is strongly suggested benefitting from GIS tools providing sufficient spatial data analysis (Duke \& Kerski, 2010; Huang, Qu, \& Chen, 2020; Milson \& Curtis, 2009). Thus, spatial and systems thinking skills can be more effectively provided.

6. According to the findings, it was determined that the learning objectives in TPSCF were insufficient regarding some categories of systems thinking skills. These are related with organizing the systems' components and processes within a framework of relationships, making generalizations, identifying dynamic relationships within the system, understanding the hidden dimensions of the system, and understanding the cyclic nature of systems. The results again show that in order to reflect the skills for these categories into the TPSCF, the learning objectives should be reviewed in accordance with 
inquiry-based teaching. Systems thinking abilities for all these categories are acquired by students by asking questions and making observations.

\section{Limitation}

1. This study is limited with the latest version of Turkish Primary Science Curriculum Framework revised in 2018 and "The Earth and The Universe" learning area related units from 3 to 8 grades. Additionally, the learning objectives were only utilized determining spatial and systems thinking skills rather than teacher guidance book, textbooks and in-class activities.

2. The subjectivity of the analysis process as an additional limitation of this study. In-depth meanings of the learning objectives and decision of sentenced-based criteria aspect of spatial and systems thinking skills were determined by perspective of the researcher. Although expert opinions were received, recommendations open to comment were presented.

\section{References}

Anselin, L. (1999). The future of spatial analysis in the social sciences. Geographic Information Sciences, 5(2), 67-76. https://doi.org/10.1080/10824009909480516

Anthamatten, P. (2010). Spatial thinking concepts in early grade-level geography standards. Journal of Geography, 109(5), 169-180. DOI:10.1080/00221341.2010.498898

Assaraf, O. B. \& Orion, N. (2005). Development of system thinking skills in the context of earth system education. Journal of Research in Science Teaching, 42(5), 518-560.

Bednarz, S.W., Heffron, S., \& Huynh, N.T. (Eds.). (2013). A road map for 21st century geography education: Geography education research (A report from the Geography Education Research Committee of the Road Map for 21st Century Geography Education Project). Washington, DC: Association of American Geographers.

California State Board of Education. 1998. History-social science content standards for California public schools: Kindergarten through grade twelve. http://www.cde.ca.gov/be/st/ss/documents/histsocscistnd.pdf

Cox, M., Steegen, A, Elen, J. \& Leuven, K.U. (2018). Using causal diagrams to foster systems thinking in geography education. International Journal of Designs for Learning, 9(1), 34-48.

Cox, M., Elen, J. \& Steegen, A. (2019) Systems thinking in geography: can high school students do it? International Research in Geographical and Environmental Education, 28(1), 37-52. DOI: 10.1080/10382046.2017.1386413

Creswell, J. W. (2012). Educational research: Planning, conducting, and evaluating quantitative and qualitative research. Boston: Pearson Education.

Creswell, J. W. (2013). Qualitative inquiry \& research design choosing among five approaches (3nd ed.). USA: Sage.

Duke, B. A., \& Kerski, J. (2010). Geo-cool: Exploring with geotechnologies. Learning \& Leading with Technology, 38(2), 28-31.

Elbay, S. (2020). A foundational perspective for spatial thinking in relation to social studies curriculum and middle school textbooks in Turkey. Review of International Geographical Education (RIGEO), 10(2), 30-57. 
Epstein, R. A., Patai, E. Z., Julian, J. B., \& Spiers, H. J. (2017). The cognitive map in humans: Spatial navigation and beyond. Nature Neuroscience, 20, 1504-1513.

Favier, T. T., \& van der Schee, J. A. (2014). The effects of geography lessons with geospatial technologies on the development of high school students' relational thinking. Computers and Education,76, 225-236.

Geography Education Standards Project. (1994). Geography for life: National geography standards. Washington, DC: National Geographic Research and Exploration.

Gersmehl, P., \& P. Anthamatten (2008). Teaching geography CD. In P. Gersmehl (Ed.), Teaching Geography. New York: Guilford Press.

Gersmehl, P., \& C. Gersmehl (2006). Wanted: A concise list of neurologically defensible and assessable spatial thinking skills. Research in Geographic Education 8(1), 5-38.

Hanson, S. (2004). Who are "we"? An important question for geography's future. Annals of the Association of American Geographers, 94(4), 715-722.

Hooghuis, F., van der Schee, J., van der Velde, M., Imants, J., \& Volman, M. (2014). The adoption of thinking through geography strategies and their impact on teaching geographical reasoning in Dutch secondary schools. International Research in Geographical and Environmental Education, 23(3), 242-258.

Huang, Y., Qu, Y., \& Chen, Y. (2020). Research on sustainable science development education of Chinese geography textbook based on GIS visualization system. IOP Conf. Series: Earth and Environmental Science, 440, 1-15.

Ikhsan, F. A., Kurnianto, F. A., Apriyanto, B., \& Nurdin, E. A. (2018). Geography literacy of observation introduction landscape representation place for student experience (Ethnomethodology Perspective). Geosfera Indonesia, 3(2), 131-145.

Illinois State Board of Education. 1997. State goal 17: Understand world geography and the effects of geography on society, with an emphasis on the United States. http://my.ilstu.edu/ eostewa/ART309/goal17\%20SOCIAL\%20STUDIES.pdf

International Geographical Union. (2016). International charter on geographical education. Retrieved from http://www.igu-cge.org/Charters-pdf/2016/IGUç2016çdef.pdf

Jo, I., Bednarz, S. \& Metoyer, S. (2010). Selecting and designing questions to facilitate spatial thinking. The Geography Teacher, 7(2), 49-55. DOI: 10.1080/19338341.2010.510779

Kim, M. \& Bednarz, R. (2013a). Development of critical spatial thinking through GIS learning. Journal of Geography in Higher Education, 37(3), 350-366.

Kim, M. \& Bednarz, R. (2013b). Effects of a GIS course on self-assessment of spatial habits of mind (SHOM). Journal of Geography, 112(4), 165-177. DOI: 10.1080/00221341. 2012.684356

Kinzel, M. \& Wright, D. (2008). Using Geovisualizations in the curriculum: Do multimedia tools enhance geography education? Paper presented at Environmental Systems Research Institute Education User's Conference August, 2008. Paper Number: 1290

Klein, P., Pawson, E., Solem, M. \& Ray, W. (2014) Geography education for "An attainable global perspective". Journal of Geography in Higher Education, 38:(1), 17-27. DOI: 10.1080/03098265.2013.801071

Merç, A. (2011). Spatial cognition and map-reading skills of students studying social studies education and pre-school education (Unpublished Mastery Thesis). Adnan Menderes Universty, Institute of Social Science, Aydın. 
Miles, M. B., \& Huberman, A. M. (1994). Qualitative Data Analysis (2nd ed.). Thousand Oaks, CA: SAGE.

Milson, A. J., \& Curtis, M. D. (2009). Where and why there? Spatial thinking with geographic information systems. Social Education, 73(3), 113-118.

Ministry of National Education (MoNE), (2018a). Science curriculum (primary and secondary schools 3, 4, 5, 6, 7 and 8 grades). Ankara. Retrieved from Ministry of National Education http://mufredat.meb.gov.tr/ProgramDetay.aspx?PID=325

Ministry of National Education (MoNE), (2018b). Social studies curriculum (primary and secondary schools 4, 5, 6 and 7 grades). Ankara. http://mufredat.meb.gov.tr.

National Research Council (2006). Learning to think spatially: GIS as a support system in the K-12 curriculum. Washington, DC: The National Academies Press.

National Research Council (2012). A Framework for K-12 science education: Practices, crosscutting concepts, and core ideas. Washington, DC: National Academies Press.

New Hampshire Department of Education. 2006. K-12 social studies New Hampshire curriculum framework. Retrieved from https://www.education.nh.gov/sites/g/files /ehbemt326/files/inline-documents/standards-socialstudies-framework.pdf .

NGSS Lead States. (2013). Next generation science standards: For states, by states. Washington, DC: National Academies Press.

Öcal, A. (2007). The study of spatial cognition skills of 6th grade students in Primary Education Social Studies course (Unpublished Doctoral Thesis). Gazi University, Institute of Education, Ankara.

Öcal, A. (2014). New approaches in teaching social studies-1 in Turan, R., Sünbül, A.M. and Akdağ, H. (Eds.), Rethinking the ability to perceive space in the social studies course (pp. 263-278). Ankara: Pegem Academi.

Schell, E. M. \& Mohan, A. (2013). Road map for 21st century geographic education: Instructional materials and professional development. The Geography Teacher, 10(1), 6-14. DOI:10.1080/19338341.2012.758597

Senge, P. M. (2010). Education for an interdependent world: Developing systems citizens. In A. Hargreaves, A. Lieberman, M. Fullan, \& D. Hopkins (Eds.), Second international handbook of educational change (pp. 131-151). Dordrecht: Springer Netherlands.

Sweeney, L. B., \& Sterman, J. (2007). Thinking about systems: Student and teacher conceptions of natural and social systems. System Dynamics Review, 23(2/3), 285312. http://doi.org/10.1002/sdr.366

\section{Biographical Statement}

Selçuk ŞAHINGÖZ is an Assistant Professor at the Department of Educational Sciences, Faculty of Education in Kastamonu University, Turkey. He received his B.S from Gazi University in Turkey and his Ph.D. from Western Michigan University in USA. His research interest includes teaching and learning science, teacher professional development and curriculum development. 